\title{
MARÍA JESÚS RUBIERA Y SUS ESTUDIOS SOBRE TOPONIMIA HISPANO-ÁRABE
}

\author{
María J. VIGUERA MOLÍNS \\ Universidad Complutense de Madrid
}

Cuando la activa Sección Departamental de Estudios Árabes e Islámicos de la Universidad de Alicante me invitó a participar en este Homenaje que, con el acertado acuerdo que al final comentaré, han dedicado a la profesora $\mathbf{M}^{\mathbf{a}}$ Jesús Rubiera Mata, proponiéndome tratar sobre sus contribuciones toponímicas, se me representaron imágenes y sensaciones de finales de los años sesenta, cuando la profesora Rubiera, en la prestigiosísima y querida revista Al-Andalus, que era el sanctasanctórum de nuestra carrera, y su camino recto, empezó a publicar, precisamente, dos notables contribuciones sobre onomástica andalusi ${ }^{1}$ : "El significado del nombre de los Banū Ašqīūla" (1966) ${ }^{2}$ y "Dos topónimos de la frontera granadina" (1967). Compañeras ambas de Licenciatura en Filologra Semítica en la Universidad Complutense de Madrid, en aquellos mediados-finales años sesenta, y viniendo yo dos cursos después que ella, recuerdo bien la impresión admirativa e incitativa que me produjo el alarde de sabiduría y agudeza que ambos artículos representan.

En esos dos artículos iniciales la profesora Rubiera aporta la identificación del romancismo Ašqutüla, como diminutivo de aśqáliya (castellano: 'escanda'; catalán: 'escaiola'), siguiendo el hilo de una

${ }^{1}$ Referencias bibliográficas completas en la Bibliografia de $M^{a}$ Jesús Rubiera Mata incluida en este mismo volumen de su Homenaje.

${ }^{2}$ Las fechas representan el orden cronológico de Al-Andalus; las fechas de publicación real fueron dos o tres años después. 
referencia de Ibn al-Jațỉ, en su Ihạta (que aún tuvo que leerla a través del manuscrito de El Escorial), donde denominaria a esa destacadísima familia granadina como "los Banū Hubayb". Y la identificación de alManzar con Bedmar, Q.tr.s con Cuadros y Qarsis con Garciez. En ambos articulos procede a través de una documentación rigurosa y una lógica impecable, y no se detiene en la mera aportación léxica, sino que apunta la trascendencia de la documentación onomástica, mostrándose consciente de ello, en el primer caso manifestando que el juego de palabras utilizado por Ibn al-Jatị "sería una prueba más de la vitalidad de la lengua romance en el reino de Granada". Otra dimensión muy destacable en ambas contribuciones es el método, el imprescindible al tratar onomástica hispanoárabe: la atención simultánea a las fuentes árabes y a las fuentes romances, en contraste sutil y múltiple, en frontera abierta y constante.

En este punto de mi exposición, debo trasladar el objetivo de mi cámara hacia un plano más general, mencionando que estas contribuciones onomásticas de la profesora Rubiera se situaban plenamente en nuestra tradición arabista más neta, que venía dedicando atención a la antroponimia y a la toponimia árabe de la Península Ibérica, en una actividad permanente y pasando por todas las etapas de curiosidad y de investigación que caracterizan la relación de conocimiento entre el ámbito hispano y el ámbito andalusí, desde la Edad Media (con su etimologismo más o menos ingenuo) hasta hoy, en que la Onomástica ha adquirido unas dimensiones, requisitos y consecuencias tan plurales, de las cuales, en concreto sobre nuestra esfera, ofrece buena muestra la serie de los Estudios Onomástico-Biográficos de al-Andalus ${ }^{3}$.

No voy ni siquiera a resumir, ahora, cuál era el estado de los estudios onomásticos sobre al-Andalus hasta aquellos años en que la profesora Rubiera publicó sus dos mencionados primeros artículos sobre estos temas. No es momento de tal evaluación, pero, como en cierta manera haya que tener en cuenta aquel estado de la cuestión, para situar cualquier labor individual, remitiré a las consideraciones generales, y muy expresivas, de Juan Vernet, en su síntesis sobre "Toponimia

${ }^{3}$ Volúmenes I y VI, ed. M. Marin (Madrid, 1988 y 1994); II y III, ed, por $M^{2}$ L. Ávila (Granada, 1989 y 1990); IV, ed. L. Molina (Granada, 1990); y V, ed. M. Marín y J. Zanón (Madrid, 1992). 
arábiga"4, apreciando, con su bibliografía crítica introductoria, los avances al respecto desde el siglo XVIII, especialmente, en adelante. Contamos también con las referencias que pueden encontrarse en el trabajo de Julio Samsó, "Los estudios sobre el dialecto andalusí, la onomástica hispanoárabe y los arabismos en las lenguas peninsulares desde $1950^{15}$, y en el de José $\mathrm{M}^{\mathrm{a}}$ Fórneas, "Elementos para una bibliografía lingürstica básica sobre al-Andalus"'. El mismo J.M. Fórneas, en colaboración con Darío Cabanelas ${ }^{7}$, ha apuntado reflexiones de necesaria consideración, por describir muy adecuadamente cuanto representa esta parcela de investigación, y cómo ha sido sentida, valorada y realizada; su cita, aunque larga, me parece imprescindible ${ }^{8}$ :

"El conocimiento del árabe hispánico constituye un instrumento básico para comprender más profundamente aspectos muy variados de la cultura española en las edades Media y Moderna, como resultado de la convivencia e interconexión de dos pueblos, cuyo vehículo de relación más importante fue este dialecto. Entre los aspectos aludidos conviene subrayar, por su mayor riqueza $y$, desde nuestro punto de vista, por ser fuentes secundarias de relevante interés para el estudio del haz dialectal andalusí, la antroponimia, la toponimia y el gran número de arabismos que aún perviven en las lenguas peninsulares. A estos dos últimos campos -toponima y arabismos- se viene prestando atención preferente, empleándose, aunque no por todos, métodos cada vez más depurados, con una visión más integral del entorno semántico y valorando, además, el sustrato latino y el adstrato mozárabe, especialmente en lo que a toponimia se refiere".

${ }^{4}$ Enciclopedia linguística hispánica, I, Madrid, 1960, pp. 561-578. XLVII.

5 Índice Histórico Español, XVI (1970 [publicado en 1977]), pp. XI a

'Actas de las Jornadas de Cultura Árabe e Islámica (1978), Madrid, 1981, pp. 45-107.

${ }^{7}$ Ponencia conjunta titulada: "Estado lingüístico de al-Andalus en torno al siglo XI: Estudios y perspectivas", publicada en las Actas citadas en la nota anterior, pp. $25-43$.

${ }^{8}$ Ponencia citada, p. 27. 
Y también esta otra evaluación, certera y muy representativa, notando respecto a los estudios de toponimia y antroponimia: "la tendencia cada vez mayor al enfoque científico-estadístico (que no excluye, sino que da solvencia cientifica a síntesis divulgadoras), al recurso constante a índices "secos" de topónimos y antropónimos, a estudiar monográficamente por zonas tipos de vocablos o fenómenos lingǘsticos. Creemos que los avances han sido grandes. $Y$ es evidente la novedad y aún escasa bibliografía dentro de la antroponimia, de horizontes singularmente prometedores en un terreno tan rico $y$ "proteico" como el peninsular".

Tal era el "ambiente" en relación con la onomástica. Se tenía la certeza, con algún matiz distinto al actual, de que la onomástica hispanoárabe representa una de las confluencias más notables entre lo árabe y lo romance, con importantes y numerosísimos reflejos conectados, que constitufan una gran fuente de documentación, recabándose de ella las informaciones entonces prioritariamente demandadas, como eran la linguística y la geográfica, y mucho menos la sociológica, dimensión que, como luego insistiré, cada vez ha conducido más hacia un análisis onomástico productivo de conocimientos sobre componentes de la población, formas de poblamiento y organización territorial.

La cantidad y el interés de la onomástica hispanoárabe "compartida" venía convocando, pues, muchos esfuerzos estudiosos, con resultados numerosos y brillantes, sobre todo en toponimia, y era labor valoradísima, porque seguía, como sigue, quedando mucho trabajo aún por hacer. En este ambiente de atención esmerada hacia la onomástica, que, según más o menos acierto a evocar, había en la Escuela de Estudios Árabes, se iniciaron, pues, las investigaciones al respecto de la profesora Rubiera. Todos sabemos quiénes eran los maestros que tuvimos, en aquellos años sesenta y setenta, en aquella Escuela -inolvidable, y "nuestra"; tan lejana-. No voy a recordar aquí otro nombre que el de don Elías Terés (1915-1983), de quien la profesora Rubiera fue discipula directa. $Y$, en relación con su magisterio, creo que ahora debo resaltar sus valiosas reflexiones metodológicas, sobre

${ }^{9}$ Ponencia citada, p. 41. 
la investigación onomástica, vertidas al compás de sus publicaciones ${ }^{10}$. Teoría y práctica toponímica muy importante, que llenó una época y proyectó sobre la siguiente su base, es posible que con trascendencia mayor de la que a primera vista captamos. Sobre esta situación y ambiente es significativo cuanto manifiesta la profesora Rubiera en su reseña "Los estudios de toponimia hispano-árabe a la luz de dos publicaciones recientes" 11 , o en su confesión emotiva de que "aprendio más Historia de España en los topónimos que en ninguna otra parte, a través de las obras de dos grandes filologos y arabistas.... D. Jaime Oliver Asín y D. Elías Terés Sádaba"12.

Tras aquellos dos artículos, con fechas de publicación en 1966 y 1967, la toponimia no vuelve a concretarse en publicaciones de la profesora Rubiera hasta 1982. Desde luego, sus conocimientos sobre onomástica andaluś están positivamente presentes en sus incesantes publicaciones entre tanto, sobre literatura e historia de al-Andalus, pero el tema no reaparece, monográficamente, hasta el artículo "Significado de algunos topónimos árabes de Aspe" ${ }^{13}$. Se inicia así una nueva etapa, que, claro está, se sustenta en sus antecedentes, pero que contiene ya características muy precisas, y distintas, que se continúan hasta hoy.

Esta nueva etapa produce una obra numerosa, con una veintena al menos de publicaciones, muchas de las cuales se reparten por editoriales, obras colectivas y revistas del Levante peninsular, del Sharq alAndalus, donde $\mathbf{M}^{\mathbf{a}} \mathrm{J}$. Rubiera, dejando Madrid, se instala, y donde pasa a ejercer su docencia y su investigación. Sobre el terreno, recibe el impacto directo de la abundantísima toponimia de origen árabe; le llega el enorme interés de todo tipo de gentes, la notable y noble

${ }^{10}$ Recordemos su culminación en Materiales para el estudio de la toponimia hispanoárabe. Nómina fluvial, Madrid, 1986, con nota preliminar por Joaquín Vallvé, donde alude a la importancia de su contribución toponímica "quizá la [dedicación] que le atraía con más fuerza".

${ }^{11}$ Reseña de los recién citados Materiales... Nómina Fluvial, de Elías Terés, y de La división territorial de la España musulmana, de Joaquín Vallvé: Sharq al-Andalus, 4 (1987), pp. 365-366.

${ }^{12} \mathrm{M}^{2} \mathrm{~J}$. Rubiera, Villena en las calzadas romana y árabe, Villena-Alicante, 1985, espec. p. 8.

${ }^{13}$ La Serranica, 36 (1982), pp. 17-18. 
curiosidad local por conocer el pasado de sus tierras; es requerida por la actividad pluridisciplinar, por el amplio y admirable desarrollo de la Arqueología; responde con su saber, en unos tiempos en que las autonomías suscitan el conocimiento de la propia historia, y en que las Universidades y la investigación atienden a estas demandas, algunas veces efervescentes, como se han manifestado en ocasiones ${ }^{14}$. Sus contribuciones y su atención al interés circundante han sido premiadas, en el curso del diálogo entorno social-historiador que la profesora Rubiera ha sabido mantener, en concreto con sus estudios sobre toponimia: en 1984 recibio el Premio "Ciudad de Benidorm" de Investigación; al año siguiente el Premio del "I Certamen de Investigación sobre Villena y su comarca".

Desde los años ochenta, el cambio historiográfico ha ido cuajando. En los estudios toponímicos se plantean, sobre todo, cuestiones de poblamiento, de organización territorial, y análisis y deducciones acerca de los elementos de población ${ }^{15}$.

Todas estas dimensiones y atenciones están en la práctica investigadora de la profesora Rubiera, cuya producción sobre toponimia, desde 1982 hasta hoy puede clasificarse en varios apartados, aunque no siempre ofrezcan materia independiente, y algunos tendrfan cabida en más de una de las siguientes clasificaciones, que han de considerarse sobre todo orientadoras ${ }^{16}$ :

\section{1: Planteamientos generales:}

- Villena en las calzadas romana y árabe (1985).

${ }^{14}$ Véase por ejemplo Míkel de Epalza, "Toponímia àrab a Catalunya", Serra d'Or, XXXVI (marzo, 1994), pp. 164-165.

${ }^{15}$ Sobre esto, a nivel general, pueden verse mis reflexiones en la ponencia "Andalucía islámica (siglos VIII-XV): territorio, poblamiento y comunicaciones", II Congreso de Historia de Andalucía (1991). Actas, Córdoba, 1994, espec. pp. $10-11$.

16 Referencias completas pueden hallarse en la "Bibliografía de $\mathbf{M}^{\text {a }} \mathrm{J}$. Rubiera", en este volumen de Homenaje. 
- (Colab. con M. de Epalza) Los nombres arabes de Benidorm y su comarca (1985) y Els noms drabs de Benidorm i la seua comarca (1985).

- "El vocablo árabe 'sikka" en su acepción de vía y sus posibles arabismos en la toponimia hispánica: Aceca, Seca y Villa Seca" (1986).

- (Colab. con M. de Epalza) "Estat actual dels estudis de toponimia valenciana d'origen àrab" (1986).

- "Los estudios de toponimia hispano-árabe a la luz de dos publicaciones recientes" (1987).

- "Els topònims aràbigo-catalans del Baix Segura (Alacant)" (1989).

2: Toponimia y organización del espacio, especialmente en el levante de al-Andalus:

- "Elda en el Pacto de Tudmir: camino y fortaleza" (1983).

- "Aspe, la gran calzada y el camino de la Almohaja" (1983).

- "Rafals y raales; ravals y arrabales; reals y reales" (1984).

- "Valencia en el Pacto de Tudmir" (1985).

- "Els camins àrabs de la muntanya i la Marina alacantines i una hipòtesi sobre el nom d'Alcoi" (1991).

3: Toponimia y elementos de población, especialmente en el levante de al-Andalus:

- "Significado de algunos topónimos árabes de Aspe" (1982), con materiales retomados en:

- "Toponimia arábigo-valenciana: Falsos antropónimos beréberes" (1984) y (1992).

\section{4: Toponimia/historia/geografía:}

- La Taifa de Denia (1985 y 1988, $2^{a}$ ed.)

- (Colab. con M. de Epalza) Xativa musulmana (segles VIII-XIII) (1987).

- "Los precedentes geopolíticos musulmanes del señorfo de Villena (1987).

- "El baix Vinalopó durant l'epoca àrab" (1988). 


\section{5: Otros ámbitos:}

- "Madjrịt" (1985).

- "La toponimia árabe de Madrid" (1990).

- "Introducción a la nueva edición" de Jaime Oliver Asín, Historia del nombre de Madrid (1991).

Hay que observar, además, que todas esas dimensiones ahora prioritarias en los estudios toponímicos, y referidas, como antes aludi, a cuestiones de poblamiento y organización territorial, están presentes en la teoría investigadora de la profesora Rubiera, como lo están en la práctica, según se pone de manifiesto, por ejemplo, en su contribución, en colaboración con Míkel de Epalza, acerca del "Estat actual dels estudis de toponímia valenciana d'origen àrab"17, con unas excelentes premisas metodológicas y un notable análisis del panorama, incluyendo un repaso a los repertorios de toponimia, a la etimología de los topónimos, al topónimo árabe como documento lingǘrstico, como documento histórico y como documento geográfico.

En este último apartado de este recién citado artículo, es especialmente importante la convicción de que ${ }^{18}$ : "Els topónims poden ser una font fonamental per conéixer la geografia humana o de poblament: mitjançant els toponims árabs podem descobrir com era l'hábitat d'època musulmana, les seues ciutats amb els ravals, les seues alqueries o poblaments rurals, els seus rafals o pletes per al bestiar, els seus reals o hortes, les seues almadraves ceramístiques de terra endins, les faluques de maó, els camins, els ponts, els diversos sistemes de captació d'aigua, etc. Però aquí també hem de ser conscients de certes limitacions importants. Els toponims àrabs no solen designar "institucions", com per exemple la propietat de la terra o la jurisdicció política: és la

${ }^{17} X^{\gtrless}$ Col-loqui General de la Societat d'Onomàstica. $1^{e r}$ d'Onomàstica Valenciana (Valencia, 1985), Valencia, 1986, pp. 420-426.

${ }^{18}$ M. de Epalza y M ${ }^{\mathrm{a}}$ J. Rubiera, "Estat actual....", espec. pp. 425-426. 
raó de l'error de Guichard ${ }^{19}$ en la seua interpretació dels albacars i del binomi alqueria/rafal....".

Está aludida así otra característica de la producción toponímica de $M^{a}$ J. Rubiera, que es su dimensión polémica, no soslayada cuando ha pensado que debía actuar. Creo que hace bien en replantear "el problema de si todos los Beni- [tan numerosos en determinadas áreas levantinas]... son nombres de familia. Es su parentesco fonético con la palabra latina pinna, que ha dado en castellano peña y en catalán penya, transcrita en árabe como bina y transformada después de la conquista en beni, por analogía...." ${ }^{20}$, y separar algunos que no serfan nombres de familia de los que sí lo son. Y creo que acierta al desvincular de una etimología tribal determinados topónimos, como Atzeneta de Albaida y otros de forma similar, en los que se identifica o documenta la etimología sanad ("ladera"), como también puntualiza resultados en relación con las huellas toponímicas de los Hawwāra y los Șinhāŷa, y constatando la escasez de rastros toponímicos de éstos últimos en particular, "a pesar de los almorávides y almohades, nos hace sostener la hipótesis de que no hubo una asimilación de estos beréberes tardíos a la población andalusi" 21 , que es observación considerable, y abierta a confrontaciones con datos sobre otros ámbitos peninsulares.

Para terminar, destacaré lo que me parece la gran contribución de la profesora Rubiera en sus estudios toponímicos, más allá de sus muchas aportaciones puntuales, y sería, en mi opinión, su capacidad para armonizar las referencias onomásticas dentro de una reconstrucción territorial, y ello de una forma dinámica, no estática, en la cual el proceso histórico manifiesta sus modificaciones y en la cual los diferentes elementos (viarios, defensivos, ofensivos, institucionales)

${ }^{19}$ De Pierre Guichard puede verse, al respecto, y entre otras contribuciones: "Faut-il en finir avec les berbères de Valence?", Al-Qantara, XI (1990), pp. 461474; "La toponymie tribale berbère valencienne: réponse à quelques objections philologiques", Festgabe fur Hans-Rudolf Singer, Francfort, 1991, I, pp. 125-141.

${ }^{20} \mathrm{M}^{\mathrm{a}} \mathrm{J}$. Rubiera y M. de Epalza, Los nombres árabes de Benidorm y su comarca, Benidorm-Alicante, 1984, espec. pp. 56-57.

$21 \mathrm{M}^{\mathrm{a}}$ J. Rubiera, "Toponimia aràbigo-valenciana: falsos antropónimos beréberes", Miscel-lània Sanchis Guarner, Valencia, 1984, espec. p. 320. 
desempeñan su papel, integrada y/o desintegradamente. En este sentido es modélico su trabajo Villena en las calzadas romana y arabe $e^{22}$.

Muy oportuna me parece la iniciativa de la Universidad de Alicante, de ofrecer este Homenaje a la profesora Rubiera, y en suscitar comentarios, reflexiones, críticas y alabanzas en torno a una producción científica. El comentario y la reflexión compartida es una de las mejores tareas que podemos cumplir.

22 Villena-Alicante, 1985. 